\title{
Do cerebral arteriovenous malformations increase in
}

\section{size?}

\author{
A DAVID MENDELOW, ANDREAS ERFURTH, KENNETH GROSSART, \\ PETER MACPHERSON
}

From the Institute of Neurological Sciences, Glasgow, Scotland

SUMMARY Six patients are reported with cerebral arteriovenous malformations which have enlarged over follow up periods of from 4 to 20 years. The frequency of spontaneous enlargement is estimated to range from $0.2 \%$ to $2.8 \%$ per annum. This rate of enlargement should be considered when treatment options are reviewed in individual patients, and should be added to the risk of haemorrhage.

Arteriovenous malformations of the brain are well recognised as a cause of subarachnoid and intracerebral haemorrhage. ${ }^{1}$ They are also recognised as a cause of epilepsy, although whether the epilepsy represents recurrent microhaemorrhage or scarring is debated. ${ }^{2}$ Further, it is generally accepted that shunting of arterial blood may result in cerebral ischaemia. ${ }^{3}$ However, changes in the size of these lesions has seldom béen reported, although Jennett and Galbraith ${ }^{4}$ have stated that "these collections of abnormal vessels increase in size with time", and there are several other references to enlargement. ${ }^{5-8}$ However, only four actual case reports have been cited. ${ }^{5-8}$

In order to determine whether or not cerebral arteriovenous malformations do increase in size we have studied the angiograms of those patients with an arteriovenous malformation who have had a second angiogram after an interval.

\section{Patients and methods}

At the Institute of Neurological Sciences in Glasgow from 1965 to 1985,326 patients were found to have an arteriovenous malformation on arteriography. Excluding immediate post operative angiography, nine patients had a second angiogram (4-25 years later) and in five of these the arteriovenous malformation had increased in size. Over the same period 229 arteriovenous malformations were excised and biopsied. The Department of Neuropathology recorded

Address for reprint requests: Mr AD Mendelow, Department of Neurosurgery, Newcastle General Hospital, Western Road, Newcastle-upon-Tyne, NE46BE, UK.

Received 23 September 1986 and in revised form 24 November 1986. Accepted 28 November 1986
104 necropsies at which an arteriovenous malformation was found. On the basis of a single neurosurgical service for $2.7 \mathrm{~m}$ population, these figures indicate a minimum incidence rate of 0.6 per 100,000 per annum. A further case was identified anecdotally from the Neurosurgery Department in Edinburgh and is included as a further example, but is excluded from assessment of population frequency for the West of Scotland where the other cases arose.

\section{Case I}

A 14 year old girl presented in 1972 with paraesthesia, weakness and clumsiness of the right hand. This recovered spontaneously and she was discharged without further investigation. A similar episode occurred in 1975, and this was followed by a fixed deficit with a right brachiofacial hemiplegia and aphasia. Angiography (fig la and b) revealed a large left sided arteriovenous malformation. It was felt that this was not operable and she was discharged. There were several further episodes of dysphasia and a pregnancy between then and 1979. She then developed epilepsy and subsequently had a subarachnoid haemorrhage in 1985. Angiography was repeated and demonstrated an increase in size of the arteriovenous malformation (fig lc and d).

Case 2

An 8 month old baby presented in 1967 with subarachnoid haemorrhage confirmed by lumbar puncture. An angiogram showed a small arteriovenous malformation in the basal ganglia region on the right (fig $2 a$ and $b$ ). The child's development was slow and he had a mild left hemiplegia. He presented again in late 1971 with a left lower quadrantanopia and left hemiplegia. Angiography in January 1972 revealed the arteriovenous malformation had enlarged considerably in the interval (fig 2c and d). It was felt that surgery was not feasible. In 1973 he presented again with headache and became drowsy. Lumbar puncture confirmed xanthochromic CSF. In 1977 the child became ataxic and there was a deterioration in vision. The head circumference had increased beyond the 98th percentile, and a ventriculoperitoneal shunt was inserted. In 1978 vision deteriorated 

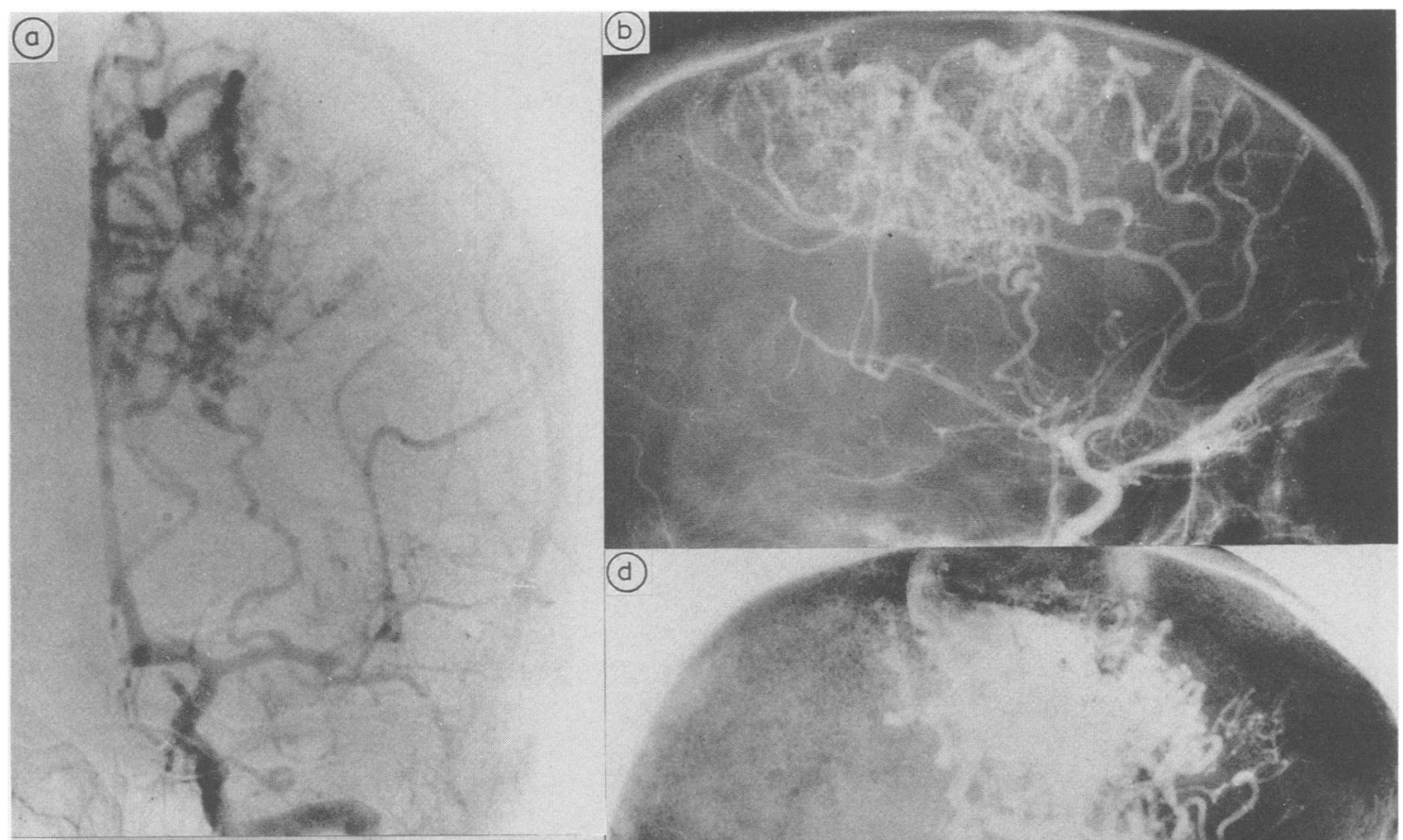

(c)

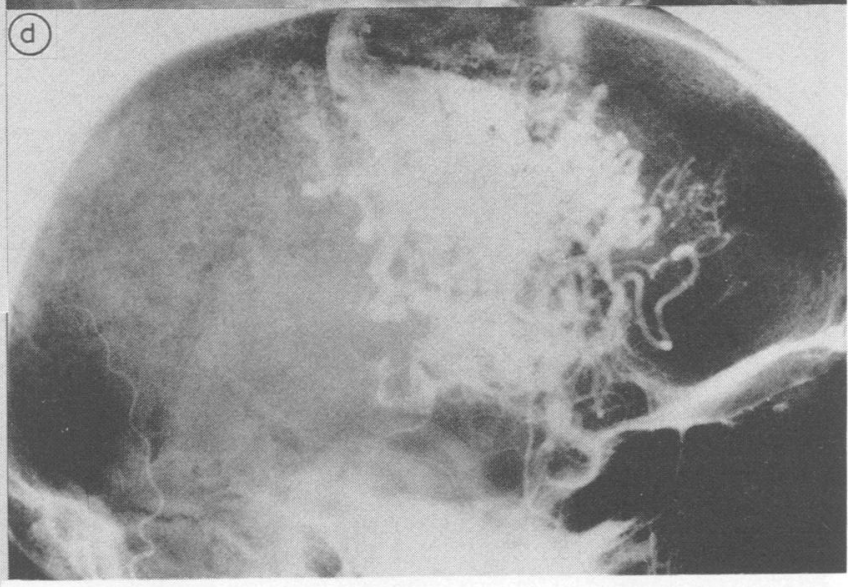

Fig 1 ( $a$ and $b$ ) Arteriovenous malformation supplied by the anterior cerebral artery and a perforating vessel (1975). ( $c$ and d) The arteriovenous malformation has enlarged and is now also supplied by middle cerebral artery branches (1985). 


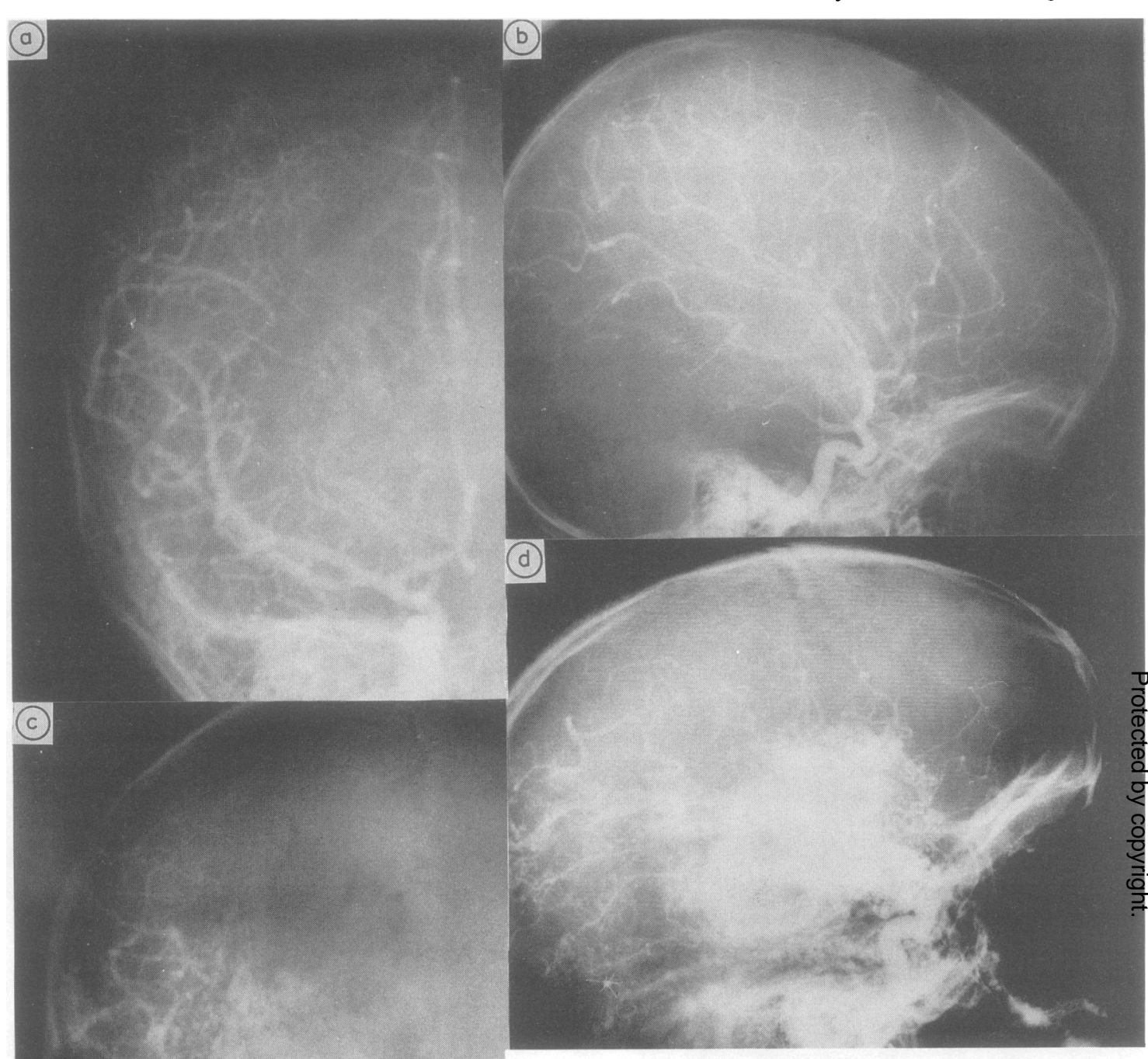

Fig 2 ( $a$ and $b$ ) Arteriovenous malformation in the basal ganglia region, supplied by perforating arteries (1967). (c and d) The lesion has enlarged considerably and it has many more feeding vessels, including some from the middle cerebral artery (1972). 


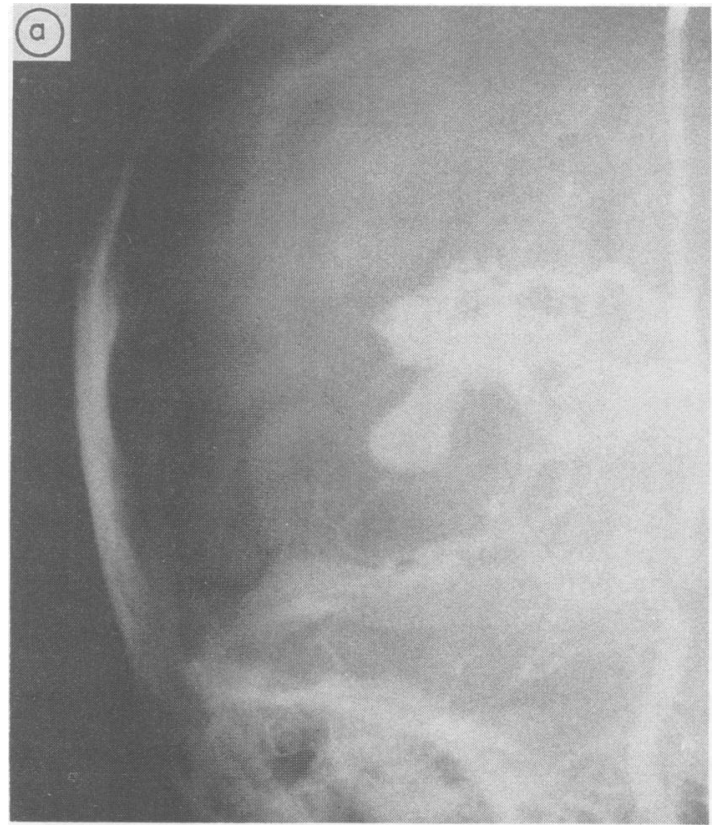

Fig 3 (a) Demonstrating a right tempero-parietal arteriovenous malformation supplied by the posterior cerebral artery (1972). (b) The abnormality has extended appreciably in all directions (1981).

further and the shunt had to be revised. The child subsequently developed subdural hygromas and died in 1979.

\section{Case 3}

An 11 year old boy presented in 1972 with headache, vomiting and neck pain. Lumbar puncture revealed blood stained xanthochromic cerebrospinal fluid. An angiogram revealed a right temporo-parietal arteriovenous malformation (fig 3a). Surgery was offered but the parents refused. In 1981 the patient presented once again with features of subarachnoid haemorrhage. There was no neurological deficit. Angiogram revealed an increase in the size of the lesion (fig 3b). At this stage the risk of operative treatment was accepted and surgery was successful. The patient made an uneventful post operative recovery and was discharged with a left homonymous hemianopia.

\section{Case 4}

A 13 year old girl presented with subarachnoid haemorrhage in 1965. An arteriovenous malformation was diagnosed and operative treatment was undertaken. It was not possible to excise the whole lesion. (fig $4 a$ and $b$ ), and a partial removal was performed. She presented with a further subarachnoid haemorrhage in 1971 when she was 30 weeks pregnant. She rapidly deteriorated into coma and an angiogram revealed there was an increase in the size of the residual arteriovenous malformation (fig $4 c$ and $d$ ). She was noted to have hydrocephalus and ventricular drains were inserted. Despite this treatment she continued to deteriorate and died.

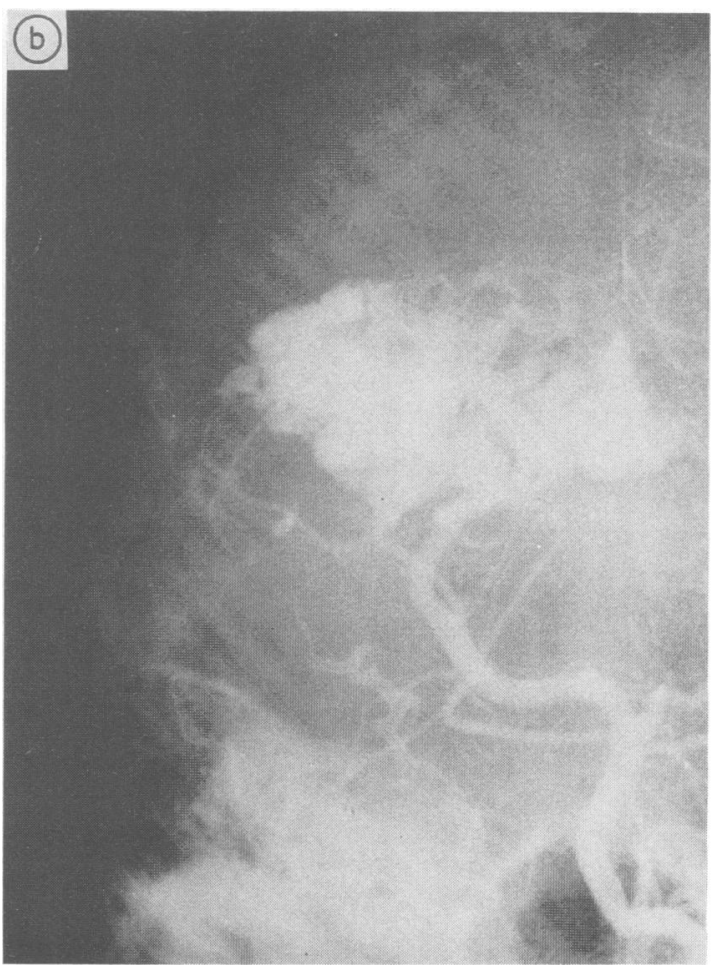

Case 5

A 24 year old woman presented with subarachnoid haemorrhage and dysphasia in 1971. Angiography revealed a small left middle cerebral artery arteriovenous malformation with a haematoma. It was considered inoperable, and she was treated with radiotherapy. She remained mildly dysphasic, and was admitted for repeat angiography in 1973 because she wanted to know whether or not she should have children. The angiogram revealed that the arteriovenous malformation was unchanged. In 1983 she presented again with a haemorrhage confirmed on CT scan. In 1984 a further angiogram was performed because stereo-radiosurgery was being planned. This angiogram showed that the arteriovenous malformation had enlarged considerably, and that it was now too large for stereo-radiosurgery. This was also confirmed on CT scan. A left fronto-temporal craniotomy was therefore performed in May 1986 and the arteriovenous malformation was totally excised. She has now recovered to the clinical state before 1983 when she was mildly dysphasic.

\section{Case 6}

This patient presented in 1966 with subarachnoid haemorrhage. Angiography showed no abnormality (fig 5a and b). The patient presented again with subarachnoid haemorrhage in 1980. Further angiography revealed a large arteriovenous malformation which was considered inoperable (fig $5 c$ and d). 

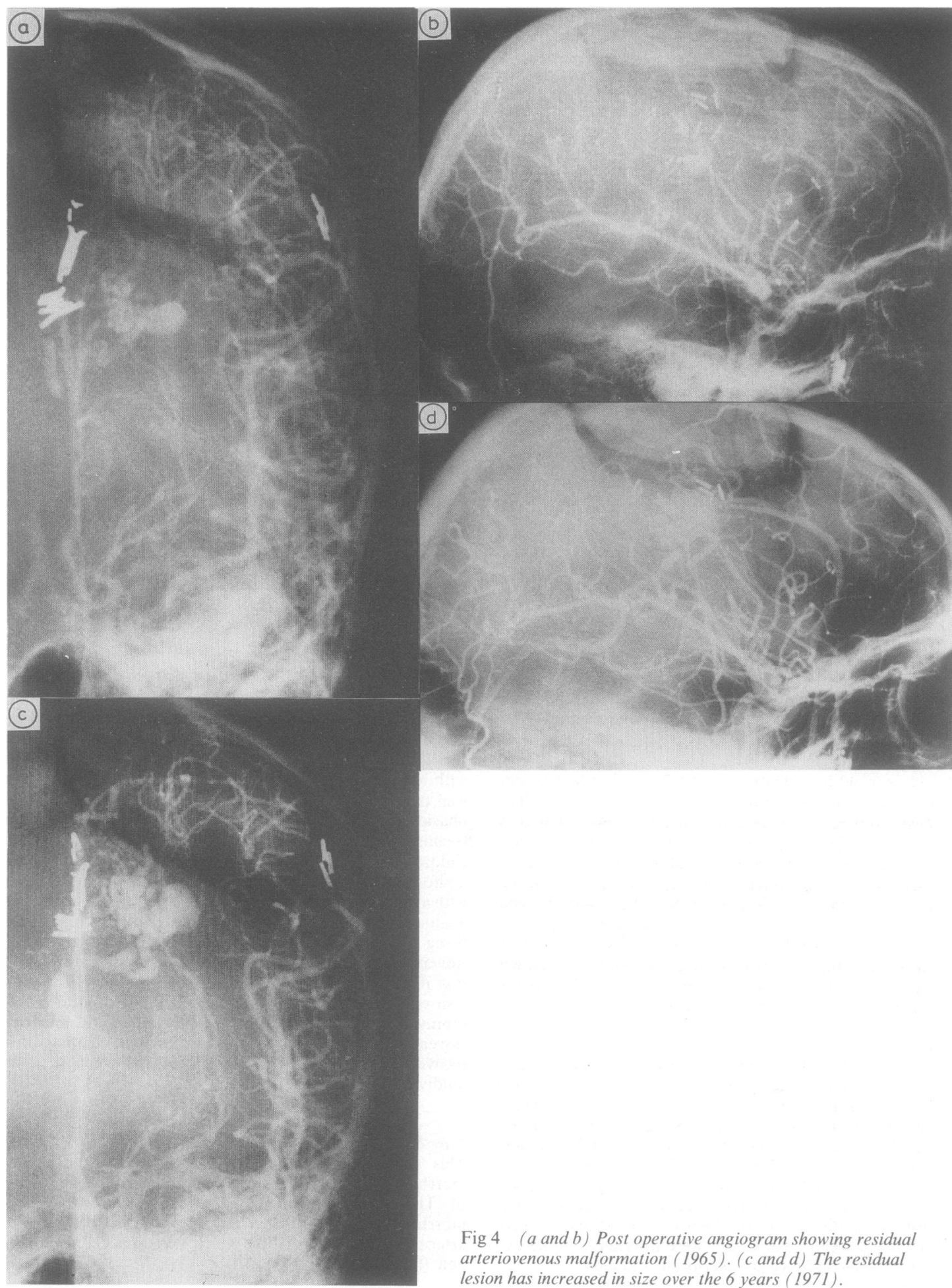

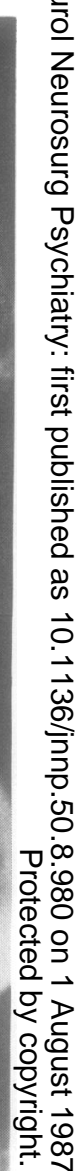

Fig 4 ( $a$ and $b$ ) Post operative angiogram showing residual arteriovenous malformation (1965). ( $c$ and d) The residual lesion has increased in size over the 6 years (1971). 


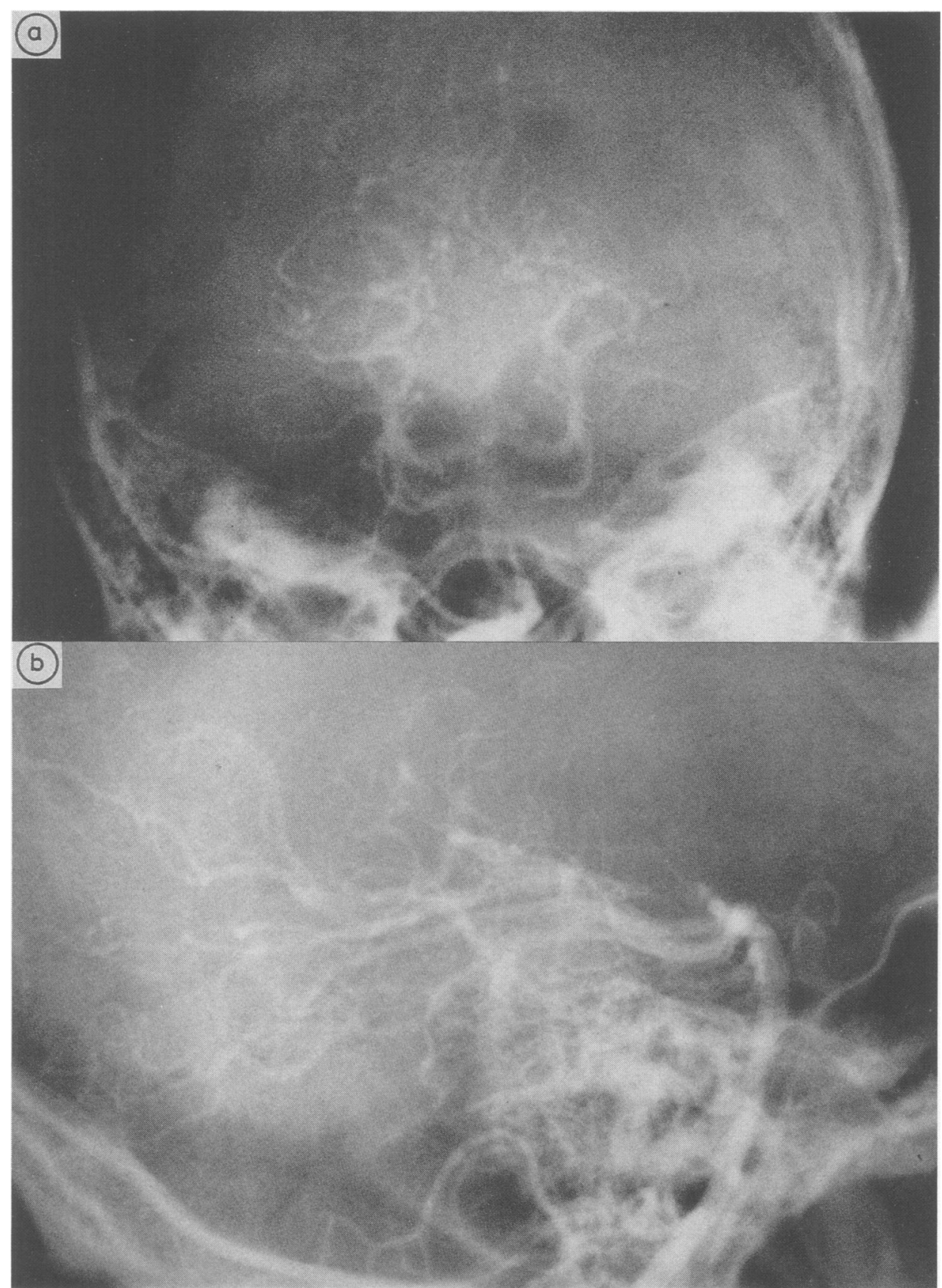

Fig 5 ( $a$ and $b$ ) Vertebral angiogram reported as normal, but in retrospect, there may be a small arteriovenous malformation supplied by the occipital branch of the right posterior cerebral artery (1966). ( $c$ and d) There is a moderately large arteriovenous malformation at the previously suspected site (1980). 


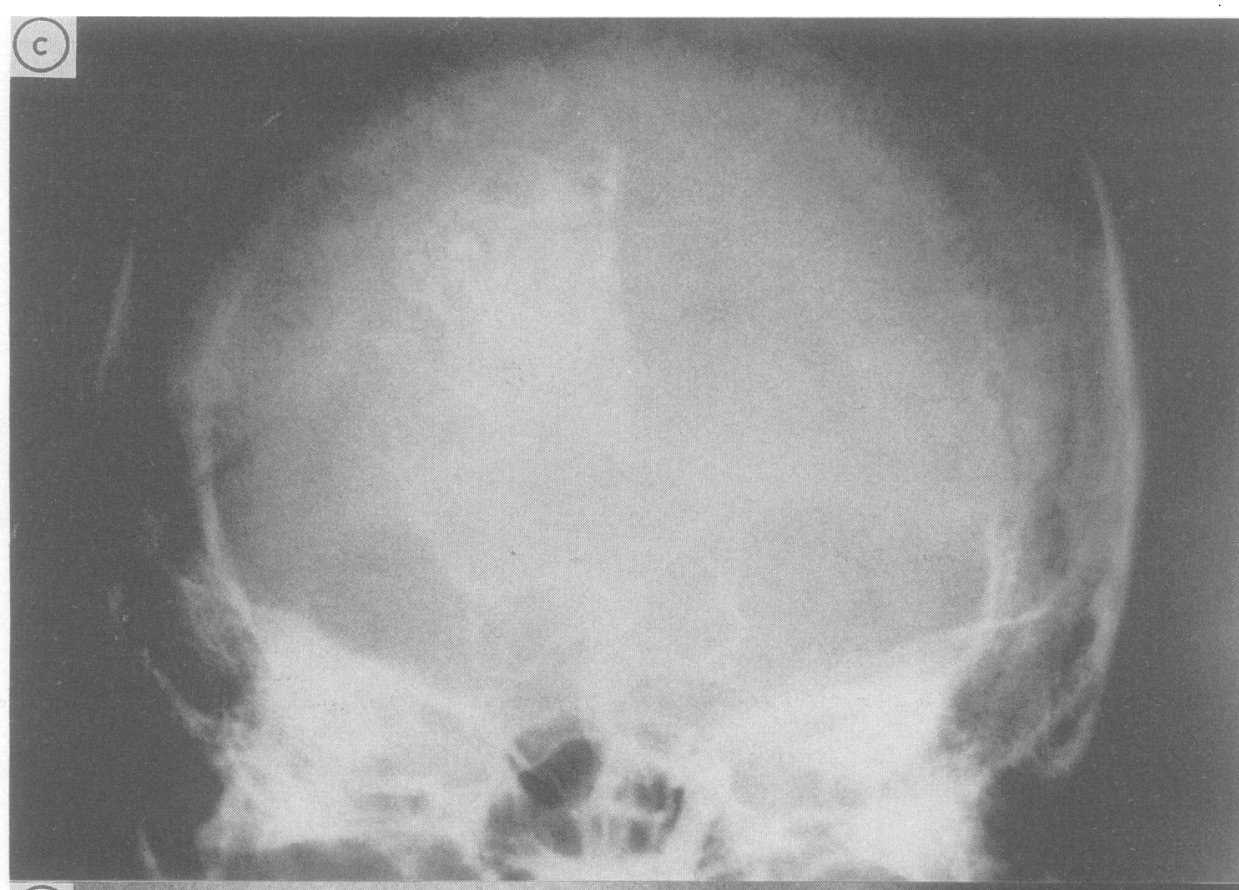

(d)

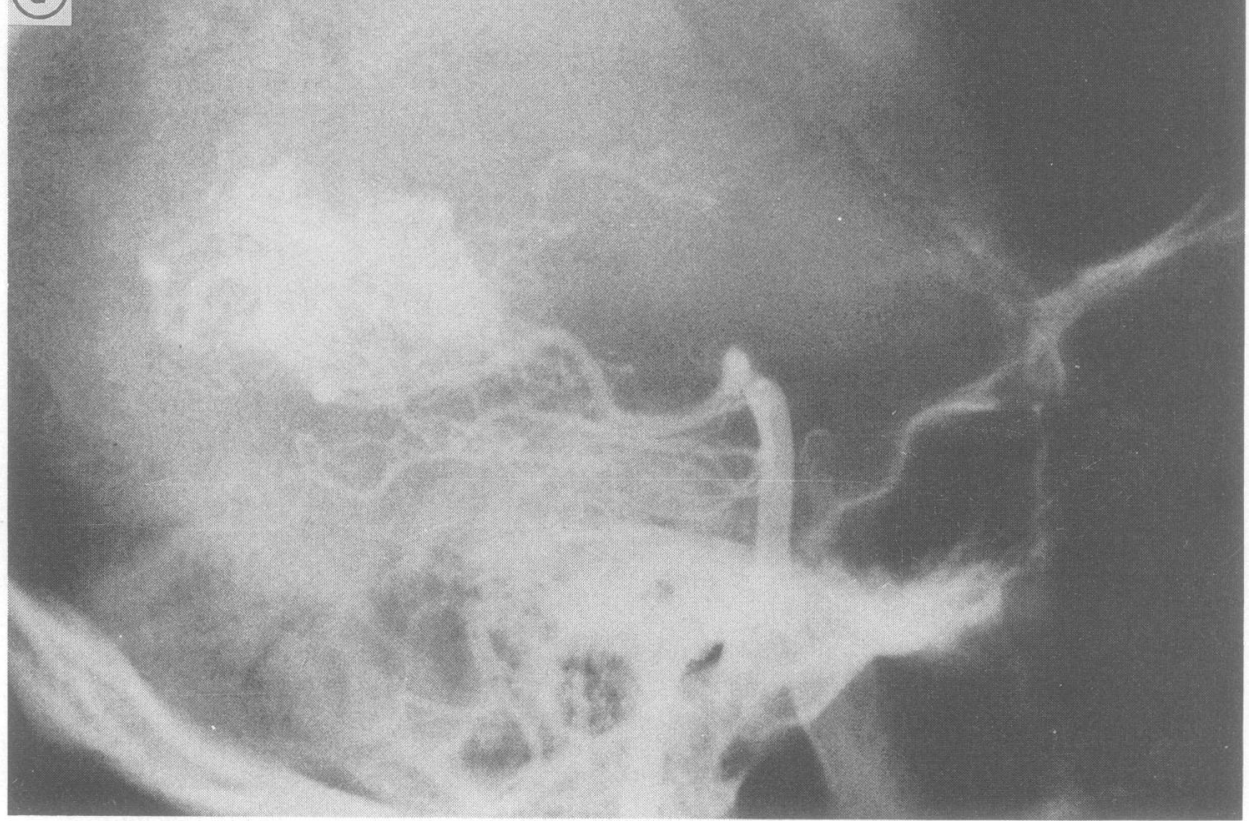

\section{Discussion}

These six cases have unequivocally demonstrated that arteriovenous malformations may increase in size. Several references to an increase in the size of an arte- riovenous malformation have been made, ${ }^{4-7}$ but only four patients in total have been reported. Olivecrona and Riives published the angiograms of a case $\sigma$ in $1948,{ }^{6}$ Shenkin et al also gave an example in $1948,{ }^{7} \mathrm{~N}$ and Potter described one in $1955 .^{8}$ In a cooperative N 
study of 563 patients with arteriovenous malformations, 453 were verified as being intracranial, ${ }^{9}$ but no reference was made to an increase in size. Similarly, in a recent report of 217 patients with arteriovenous malformations managed without surgery, enlargement was not mentioned. ${ }^{10}$ Our estimates of the population from which these patients were taken has indicated an incidence rate of 0.6 per 100,000 per annum. In the 20 years of this study 326 arteriovenous malformations were diagnosed angiographically in the Glasgow Unit. Of these, we have estimated that 113 cases did not undergo surgery and 77 of their angiograms were available for this study. Only nine patients had a second angiogram after a long follow up period. An increase in size was documented in five of these. The possible frequency with which these lesions increase in size can therefore be estimated as being between $5 / 9$ and $5 / 113$ over a 20 year period depending upon whether one considers only the nine who had a second angiogram (by self selection) or all 113 who did not undergo surgery, and who were therefore at risk. This represents a range of between $4 \%$ and $56 \%$ over the 20 year period, or $0.2 \%$ to $2.8 \%$ per year. This range covers the highest and lowest possible enlargement rates, and it is reasonable to assume that the real rate lies somewhere between these limits. Nevertheless, because the average time between the first and second angiograms was 9 years (and not 20 years) in the five Glasgow patients, the annual rate of enlargement may be even higher than these estimates would suggest.

In our six cases the patients were all young, so that the risk of enlargement may apply particularly to patients of under 30 years of age. Olivecrona and Riives ${ }^{6}$ referred to this and stated that the lesion may not give rise to symptoms initially because it is small, but the subsequent deterioration may result from enlargement which may take several decades. One of the five cases had enlarged despite surgery, although in that particular case it was acknowledged that surgery was incomplete. Another enlarged despite radiotherapy.

Our study lends further support to the argument that unruptured arteriovenous malformations should be excised not only to prevent rebleeding, but also to prevent increase in size which may result in neurological deterioration. Of greater importance is the danger that the increased size may render a previously operable lesion inoperable. It has been estimated that following haemorrhage the rebleed rate is $6 \%$ per annum in the first year and 3\% per annum thereafter.
For unruptured arteriovenous malformations the haemorrhage rate is $2 \%$ per year. ${ }^{11}$ The combined risk of haemorrhage and enlargement is therefore at least $2.2 \%$ per year. If the higher risk figure for enlargement is considered $(2.8 \%)$, then the combined risk of haemorrhage and/or enlargement for an unruptured arteriovenous malformation would be $4.8 \%$ per year. The risk to the patient of an increase in size should therefore be considered when nonoperative treatment is selected in patients with arteriovenous malformations.

We thank Mr P Harris of the Western General Hospital in Edinburgh for permission to publish Case 6. Our thanks go to Anne Semple for preparation of the manuscript.

\section{References}

1 Drake CG. Cerebral arteriovenous malformations: considerations from an experience with surgical treatment 166 cases. Clin Neurosurg 1978;26:145-208.

2 Wilson CB, York C. Intracranial arteriovenous malformations. In: Wilson CB, Hoff JT, eds. Current Surgical Management of Neurological Disease. New York: Churchill Livingstone, 1980:182-90.

3 Toennis W, Lange-Cosack H. Klinik, operative Behandlung, und Prognose der arterio-venoesen Angiome des Gehirns und Seiner Haeute. DZ Nervenheilk 1953;170:460-85.

4 Jennett B, Galbraith S. An Introduction to Neurosurgery. 4th ed. London: Heinemann, 1983:202.

5 Spetzler RF, Wilson CB. Enlargement of an arteriovenous malformation documented by angiography. Case report. J Neurosurg 1975;43:767-9.

6 Olivecrona H, Riives J. Arteriovenous Aneurysms of the brain. Arch Neurol Psychiatr 1948;5:567-602.

7 Shenkin HA, Spitz EB, Grant FC, Kety SS. Physiologic studies of arteriovenous anomalies of the brain. $\mathrm{J} \mathrm{Neu}$ rosurg 1948;5:165.

8 Potter JM. Angiomatous malformations of the brain: their nature and prognosis. Ann Roy Coll Surg England 1955;16:227-43.

9 Perret G, Nishioka H. Report on the Co-operative Study of Intracranial Aneurysms and Subarachnoid Haemorrhage. Section VI: Arteriovenous malformations. $J$ Neurosurg 1966;25:467-90.

10 Crawford PM, West CR, Chadwick DW, Shaw DM. Arteriovenous malformations of the brain: natural history in unoperated cases. J Neurol Neurosurg Psychiatry 1986;49:1-10.

11 Graf CG, Perret GE, Turner JC. Bleeding from cerebral arteriovenous malformations as part of their natural history. J Neurosurg 1983;58:331-7. 